\title{
IMAGEN DE LA CIENCIA Y DE LA TECNOLOGIA EN ESPAÑA
}

Manuel García Ferrando

\section{LA LEY DE LA CIENCIA Y EL ESTUDIO DE LAS ACTITUDES SOCIALES HACIA LA CIENCIA}

En el pasado año de 1986 fue aprobada en el Parlamento español la Ley de Fomento y Coordinación de la Investigación Científica y Técnica, la llamada Ley de la Ciencia, que pretende dar respuesta a los problemas específicos del sistema español de ciencia y tecnología. Según los autores del borrador de la Ley, el actual sistema español de ciencia-tecnología presenta tres grandes deficiencias: «la escasez de recursos humanos y materiales, su desconexión con el sistema productivo y, sobre todo, la falta de coordinación entre las distintas instancias con responsabilidad en el campo de la investigación científica y el desarrollo tecnológico» (Política Científica, diciembre 1985, pág. 4).

Como consecuencia de esta insuficiencia estructural, el sistema investigador es ineficaz frente al modelo de desarrollo tecnológico, lo que ha obligado a la importación de tecnología y a la dependencia de los países más avanzados. Según los datos utilizados por la comisión que ha elaborado el borrador de la Ley de la Ciencia, la suma total del gasto anual español de investigación en ciencia y tecnología es, aproximadamente, igual al gasto en concepto de royalties por compra de tecnología extranjera. España gasta, aproximadamen- 
te, 100.000 millones de pesetas anuales en compra de tecnología, mientras que solamente exporta por valor de 10.000 millones de pesetas.

Tal situación pretende ser modificada con la promulgación de la Ley de la Ciencia, la cual concentra su atención en cinco direcciones estratégicas: 1) gestión de la investigación como un todo; 2) definición clara de prioridades; 3) vinculación de la investigación científica al desarrollo y la innovación tecnológica; 4) incorporación de la empresa privada al esfuerzo de investigación, y 5) modernización de los organismos públicos de investigación.

Ahora bien, los esfuerzos de los legisladores por dotar al sistema español de una Ley de la Ciencia, moderna y eficaz, tienen que venir acompañados de esfuerzos paralelos para que la sociedad, como un todo, acoja los cambios científicos y tecnológicos adaptándolos a su propia dinámica social. De la aceptación de esta última premisa surge la necesidad de conocer e investigar los valores y las actitudes sociales dominantes en torno a tales temas.

En 1982, el Centro de Investigaciones Sociológicas puso en marcha una encuesta, dirigida por Pedro González Blasco y Manuel García Ferrando, acerca de la imagen de la ciencia y la tecnología en España entre la población adulta española y los diputados de aquella legislatura. Los resultados de la encuesta no se publicaron de inmediato y quedaron depositados en el Banco de Datos del CIS. Un poco más tarde preparé, con los resultados más relevantes de la encuesta, un trabajo que por diversos motivos no se publicó en aquellos momentos.

Sin embargo, en los momentos presentes, la relevancia del tema estudiado - la imagen de la ciencia y la tecnología en España-, la escasa variación que se haya podido producir en los resultados desde la fecha en que se obtuvieron (1982) y el presente año de 1987 - se trata de un rasgo estructural de lenta modificación-, y la actualidad y oportunidad del debate científico que ha originado el propio debate parlamentario de la Ley de la Ciencia, aconsejan que se publique el referido trabajo que recoge los principales resultados de la encuesta, aunque ello se haga con un poco de retraso, ya que la ausencia de estudios similares hace todavía más oportuna la difusión de tales resultados entre la comunidad académica y científica.

\subsection{Los objetivos de la investigación}

A partir de los comienzos de los años setenta parece haberse producido en el conjunto de los países occidentales una erosión en la confianza del público en general con respecto a la ciencia y la tecnología, en comparación al ambiente existente en el período que siguió a la Segunda Guerra Mundial. En el fondo de este cambio subyacen la difusión y el rigor que han alcanzado las críticas de lo que podríamos denominar de manera amplia «posturas 
ecologistas», que acusan al progreso industrial y tecnológico de una serie amplia de males que padecen nuestras sociedades, y que van desde los problemas de contaminación del aire hasta los referentes a una supuesta deshumanización de la sociedad. Los medios de comunicación de masas en las sociedades occidentales con frecuencia presentan informes cuyos contenidos denuncian los peligros de la energía nuclear, de los residuos tóxicos, de los productos químicos utilizados en la agricultura comercial, de los aditivos alimentarios y de un largo etcétera de aspectos relacionados todos ellos con el cambio social provocado por la presencia dominante de la ciencia y de la tecnología en la sociedad contemporánea.

La difusión de tales informes está produciendo indudablemente una influencia sensible en el público occidental que no resulta, ni mucho menos, positiva para el desarrollo de la ciencia. Esta situación general ha comenzado a preocupar tanto a los Gobiernos de las naciones occidentales como a la propia comunidad científica. Así, en el ámbito del país de mayor desarrollo tecnológico del mundo, los Estados Unidos, el National Science Board dedicó en 1976 una sección entera del informe elaborado con motivo del bicentenario a las preocupaciones manifestadas por los científicos acerca del nivel de desintegración del apoyo público a sus esfuerzos de investigación '. Más recientemente, el presidente de la Academia Nacional de las Ciencias de los Estados Unidos insistió en la necesidad de alterar la tendencia de incremento del escepticismo público hacia la ciencią ${ }^{\text {. }}$.

En España, ciertamente, el desarrollo de la ciencia nunca ha merecido una atención prioritaria por parte de las autoridades públicas. Inclusn cabe hablar de un complejo nacional de inferioridad en relación al quehacer científico, reflejado en el expresivo y ya clásico «ique inventen ellos!». En fechas tan recientes como mediados del mes de noviembre de 1980, un grupo muy importante de científicos españoles, encabezados por nombres tan prestigiosos como Grande Covián, Cabrera, Severo Ochoa, Grisolía, Rodríguez Delgado y otros firmó un manifiesto en el que se denunciaba la penuria de la ciencia española: «La situación de la ciencia en España es indigna de un país desarrollado y celoso de su independencia... Es desalentadora la falta de atención del Gobierno y de las fuerzas políticas y económicas del país a esta realidad. Con una torpe visión del futuro, hemos postergado los aspectos creativos de la investigación a un pragmatismo a corto plazo propio de una sociedad colonial...» ${ }^{3}$. El manifiesto abunda en la falta de apoyo y comprensión públicos y oficiales a los esfuerzos de los científicos españoles, y termina con

' National Science Board, Science at the Bicentennial: A Report from the Research Community, Washington, D. C., U. S. Government Printing Office, 1976.

'Philip Handuer, «Public doubts about science», Science, 208, 1980.

${ }^{3}$ Varios firmantes, «Manifiesto de los científicos españoles ante la situación de la investigación del país», aparecido a mediados de noviembre de 1980 en los principales periódicos de ámbito nacional. 
una llamada al sentido de la responsabilidad del Estado para impulsar la investigación.

Desde la publicación del manifiesto, el debate público sobre la situación de la ciencia en España no ha cesado, y las promesas oficiales de mayor apoyo a la investigación parecen hacerse efectivas poco a poco. Así, en unas declaraciones recientes del científico español más laureado, el profesor Severo Ochoa, manifestaba encontrarse "más satisfecho que en otras ocasiones porque desde hace un año se registra una actitud más positiva hacia la ciencia en España, tanto en medios oficiales como privados» ${ }^{4}$. Sin embargo, las declaraciones de Ochoa no se corresponden con otras declaraciones públicas realizadas por diferentes científicos, que insisten en la falta de apoyo que recibe la investigación científica en la sociedad española.

Además, cabe suponer que la falta de apoyo histórico a la ciencia en España tiene que haberse reforzado, a nivel de imagen pública, con el «pesimismo tecnológico» que parece haber invadido a amplias capas de la población de los países occidentales, y que es de esperar que también se haya producido en España. Ahora bien, la anterior discusión no ha dejado de producirse principalmente entre científicos y expertos, y las más de las veces no hace otra cosa que reflejar posiciones e intereses personales cuando se habla de las posturas dominantes en la sociedad española en relación a la ciencia y la tecnología. Sin embargo, se echan en falta las discusiones basadas en resultados de investigaciones concretas que, desde una óptica sociológica, desvelen el complejo entramado social en el que se asienta el mundo científico y tecnológico en la sociedad española. En concreto, cabe preguntarse ahora lo siguiente:

¿Hasta qué punto apoya la población española la investigación científica y reconoce su importancia? ¿Cuál es el grado de difusión del «pesimismo tecnológico» entre los españoles? ¿Cuántas personas apoyan las innovaciones tecnológicas y cuántas las rechazan? Desde luego, y a partir de las discusiones y declaraciones de científicos y políticos, no se pueden responder cabalmente las anteriores cuestiones, y es que la hasta ahora pobremente desarrollada sociología de la ciencia española no ha tenido ocasión de disponer de resultados científicos fiables al respecto.

Con el fin de rellenar, en parte, este vacío en el panorama de la sociología de la ciencia española, se ha realizado una investigación cuyo objetivo general ha sido el de trazar los rasgos definitorios de la ciencia y de los científicos en España. A tal fin, se realizaron sendas encuestas entre el público general y los diputados de la legislatura anterior (1979-1982), con el fin de obtener resultados que permitieran la comparación de las imágenes de las ciencias y de los científicos, que mantiene el público general, y las que pre-

${ }^{4}$ Despacho de la Agencia Efe aparecido el 4 de julio de 1982 en el periódico El País. 
dominan entre el colectivo de mayor responsabilidad político-legislativa de la sociedad, como es el que integran los diputados pertenecientes a la totalidad de partidos políticos que forman el Parlamento.

\subsection{Nota metodológica}

La encuesta realizada al público en general tuvo como ámbito el universo de la población española mayor de 18 años, residente en hogares familiares de la Península, islas Baleares y Canarias.

La muestra, con un tamaño teórico de 1.200 individuos, es de carácter aleatorio estratificado por cruce de región-hábitat, y ha permitido ofrecer unos resultados que para un nivel de confianza del 99,5 por 100 comporta un margen de error de más o menos el 3 por 100 .

El cuestionario se administró personalmente en el domicilio del entrevistado por la red de entrevistadores del Centro de Investigaciones Sociológicas, durante el mes de junio de 1982.

La encuesta realizada entre los diputados incluyó a la totalidad de los parlamentarios que ocupaban su cargo en la primavera de 1982. El procedimiento seguido consistió en enviar un cuestionario por correo a la dirección particular de cada uno de los diputados, acompañada de una carta en la que se explicaban los móviles científicos de la investigación. Realizado el primer envío de los cuestionarios, se dejó transcurrir un tiempo prudencial para realizar un segundo envío-recordatorio. De este modo se logró que devolvieran el cuestionario debidamente cumplimentado 108 diputados, es decir, aproximadamente un 30 por 100 del colectivo de parlamentarios, lo que ofrece una tasa de respuesta que, para lo que es habitual en las encuestas por correo, puede considerarse satisfactoria. Además, la distribución porcentual del partido de pertenencia de los diputados - 48 por 100 de UCD, 40 por 100 del PSOE y 12 del resto de los partidos - nos hace suponer que las respuestas obtenidas tienen el suficiente grado de representatividad como para admitir como válidos los argumentos que se desarrollan en el análisis que sigue.

El cuestionario utilizado fue común para la población general y para los diputados, con la excepción de algunas preguntas de identificación que tuvieron que formularse de forma diferente según se tratara de un tipo de población u otro. Pero para la totalidad de los temas básicos estudiados se ha podido mantener el criterio comparativo gracias a la identidad de las preguntas formuladas. 


\section{IMAGEN GENERALIZADA DE LA CIENCIA}

La ciencia, de una forma abstracta y generalizada, goza de buena imagen entre la población general, y es aún mejor entre los diputados. Esta es la conclusión que cabe obtener de la distribución de respuestas dadas a la siguiente pregunta: «En general, ¿piensa usted que la ciencia aporta al hombre más cosas buenas que malas, más cosas malas que buenas o aproximadamente igual de cosas buenas que de malas?", respuestas que se contienen en la tabla 1.

\section{TABLA 1}

Opinión sobre el carácter de la aportación de la ciencia a la Humanidad

\begin{tabular}{|c|c|c|}
\hline La ciencia aporta al bombre & $\begin{array}{c}\text { Población } \\
\text { general }\end{array}$ & Diputados \\
\hline 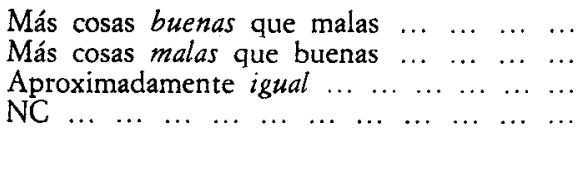 & $\begin{array}{r}64 \\
8 \\
20 \\
9 \\
\\
(1.196)\end{array}$ & $\begin{array}{c}100 \\
- \\
- \\
(108)\end{array}$ \\
\hline
\end{tabular}

Las respuestas de los diputados apuntan, sin excepción, en una única dirección: la de reconocer todos ellos el carácter positivo de las aportaciones científicas al bienestar de la Humanidad. Entre la población general, la posición dominante apunta en la misma dirección, pero ya no se produce unanimidad como en el caso anterior, ya que, frente al 64 por 100 de individuos que reconocen las aportaciones positivas de la ciencia, aparece un 8 por 100 de entrevistados que considera que la ciencia aporta más cosas malas que buenas, y otro 20 por 100 que estima como equilibradas las aportaciones positivas y negativas de la ciencia.

Hay que señalar que la población «pesimista» acerca del carácter de las aportaciones científicas no se reparte al azar entre el conjunto de la sociedad, sino que tiende a concentrarse con preferencia entre grupos de individuos caracterizados por variables significativas. Así, entre las personas que se consideran de extrema izquierda, el 27 por 100 considera malas las aportaciones de la ciencia, mientras que dicho porcentaje va descendiendo según nos movemos hacia el lado derecho de la escala ideológica, como se observa a continuación: 


\begin{tabular}{|c|c|c|}
\hline Escala ideológica & $\begin{array}{c}\text { Personas que } \\
\text { consideran } \\
\text { malas las } \\
\text { aportaciones } \\
\text { científicas } \\
(\%)\end{array}$ & $\begin{array}{c}\text { Personas que } \\
\text { consideran } \\
\text { buenas las } \\
\text { aportaciones } \\
\text { científicas } \\
(\%)\end{array}$ \\
\hline 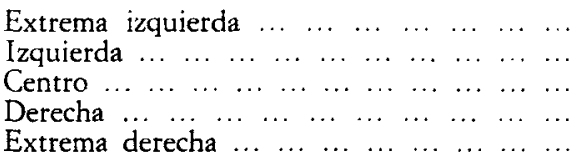 & $\begin{array}{r}27 \\
9 \\
5 \\
2 \\
0\end{array}$ & $\begin{array}{l}45 \\
65 \\
74 \\
73 \\
70\end{array}$ \\
\hline
\end{tabular}

Como se observa, la relación entre ideología política y consideración de la ciencia es perfecta. De un 27 por 100 de posturas «crítico-negativas», en relación a la ciencia entre las personas identificadas con la extrema izquierda, se pasa a la ausencia total de tales posturas entre las personas identificadas con la extrema derecha. En las posiciones de izquierda, centro y derecha, que, por otro lado, son las que atraen a la mayoría de la población -los grupos extremistas representan, en términos cuantitativos, una pequeña minoría-, los porcentajes de «pesimistas» desciende desde el 9 por 100 entre las gentes de izquierda al 2 por 100 entre los que se identifican con la derecha, representando el centro, como cabía esperar, una posición intermedia del 5 por 100 .

Siguiendo esta misma línea argumental del tipo de relación existente entre preferencias ideológicas y percepción de las consecuencias sociales de la ciencia, se observa que el porcentaje más alto de consideración negativa de la ciencia se da entre los votantes del PCE (13 por 100), mientras que el porcentaje más bajo aparece entre los votantes de AP (2 por 100). Tales resultados ponen de manifiesto el trasfondo ideológico de las imágenes de la ciencia, destacándose con toda claridad las actitudes más positivas hacia la derecha, mientras que las negativas tienden a concentrarse en el lado izquierdo del espectro ideológico.

Tales resultados ponen de manifiesto que la variable que más influye en la preparación de la ciencia es de naturaleza ideológica, toda vez que las diferencias que se producen en la consideración del carácter positivo o negativo de las aportaciones de la ciencia son mayores cuando se consideran las diversas posiciones en la escala ideológica -27 unidades porcentuales entre la extrema izquierda y la extrema derecha en la consideración negativa de la ciencia- que cuando se consideran otras variables relevantes, tales como nivel de estudios, lugar de residencia, sexo, ocupación, etc. También ha quedado claro del anterior análisis que un mayor nivel de educación y conocimientos refuerza la imagen positiva de la ciencia, con la excepción de aquellas perso- 
nas, minoritarias, pero muy activas en sus manifestaciones públicas, que, identificadas con ideologías radicales de signo izquierdista, tienden a adoptar posturas crítico-negativas en relación a la ciencia y a la tecnología, con independencia de su nivel de estudios. A lo largo del presente estudio tendremos más ocasiones de analizar el efecto de la ideología en la consideración de lo científico y de lo tecnológico.

\section{GRADO DE ACEPTACION DE LA TECNOLOGIA}

El reconocimiento generalizado de las aportaciones positivas de la ciencia entre la población española se complementa con un nivel bastante alto de aceptación de la tecnología. Ante la siguiente pregunta: «¿Podría usted decirme qué grado de confianza le merecen los nuevos avances tecnológicos (nuevas máquinas, nuevos descubrimientos, etc.) para resolver los problemas más importantes que tiene la Humanidad?», las respuestas aprobatorias claramente superan a las respuestas que revelan desconfianza.

En efecto, y tal como se observa en los resultados que se contienen en la tabla 2, la mayoría de la población se sitúa en la parte superior de la escala, posiciones que revelan un grado de confianza alto, mientras que sólo grupos minoritarios de población se colocan en el extremo inferior de la escala que revela escasa confianza en los avances tecnológicos.

\section{TABLA 2}

Grado de confianza que le merecen a la población los avances tecnológicos para resolver los problemas de la Humanidad

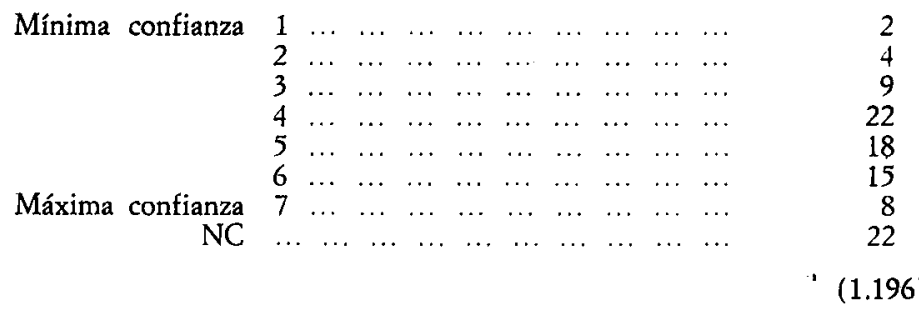


Esta distribución del grado de aceptación de la tecnología que manifiesta la población española es bastante similar al que muestra la población alemana en un estudio ${ }^{5}$ patrocinado por la empresa Siemens AG y realizado en 1980 sobre una muestra de 2.000 ciudadanos de la Alemania Federal. Agrupando los resultados obtenidos, de tal forma que las posiciones 1 a 3 se identifican con el escepticismo, la posición 4 con la neutralidad y las posiciones 5 a 7 con la aprobación, se puede formar el siguiente cuadro, que permite la comparación de las actitudes de la población española y de la población alemana con respecto a la tecnología.

\section{TABLA 3}

Comparación del grado de aceptación de la tecnologia entre la población española y la población alemana

\begin{tabular}{|c|c|c|}
\hline Actitud bacia la tecnologia & $\begin{array}{l}\text { Población } \\
\text { española }\end{array}$ & $\begin{array}{c}\text { Población } \\
\text { alemana }\end{array}$ \\
\hline 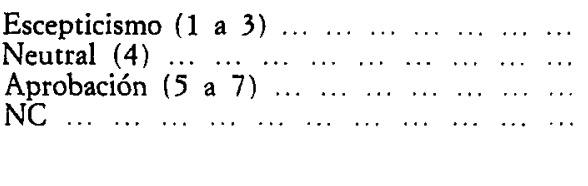 & $\begin{array}{c}15 \\
22 \\
41 \\
22 \\
(1.196)\end{array}$ & $\begin{array}{c}16 \\
20 \\
49 \\
15 \\
(2.000)\end{array}$ \\
\hline
\end{tabular}

$1=$ muy escéptico hacia la tecnología.

$7=$ muy positivo hacia la tecnología.

Así, pues, un poco menos de la mitad de ambas poblaciones manifiesta actitudes positivistas hacia la tecnología, mientras que otro 20 por 100 permanece indeciso y un minoritario 15 por 100 mantiene actitudes de escepticismo en relación a los avances tecnológicos. No deja de ser interesante la analogía de ambas distribuciones, ya que, caso de no deberse al puro azar, puede interpretarse como manifestación de la estructura actitudinal de la población de las sociedades tecnológicamente avanzadas, estructura que presenta un recorrido que va desde el escepticismo hasta la aceptación total. El pesimismo extremo es propio de grupos minoritarios de población que, desde posiciones ideológicamente de izquierda radical, adoptan una militancia activa en su rechazo de la ciencia y de la tecnología. La aceptación incondicional de la ciencia la manifiestan grupos más amplios de población que, sin embargo, no son activos en la manifestación pública de sus preferencias. En todo caso,

Reinhold BERG HER, «Technology between self-indulgence, scepticism and necessity», Siemens Review, vol. XĹVIII, núm. 3, 1981, pp. 28-32. 
y en espera de disponer de los resultados de estudios similares al presente que se puedan realizar en otros países occidentales avanzados, queda claro la existencia de actitudes contrapuestas en relación a la ciencia y a la tecnología, que revelan, por otro lado, las propias contradicciones que los avances tecnológicos producen en los procesos de cambio social de nuestras sociedades.

El perfil dominante de las personas que mantienen actitudes escépticas hacia la tecnología es el de joven varón menor de 24 años, residente en grandes ciudades, con nivel de estudios variable, profesión poco cualificada o en paro e ideología radical de izquierdas. El perfil dominante de las personas que aceptan plenamente la tecnología, y siempre según los resultados obtenidos en la presente investigación, es el de varón de edad joven o intermedia, residente en ciudades de tamaño intermedio, con nivel de estudios superior, profesión cualificada o estudiante universitario e ideología de derechas.

\section{CONOCIMIENTO DE LA TECNOLOGIA}

Existe un evidente desfase entre la amplia aceptación de la tecnología y el escaso conocimiento que manifiesta tener la población sobre la misma. Ante la pregunta que inquiere por los conocimientos que se tienen al respecto, y que se formuló del siguiente modo: «Por lo que se refiere a sus propios conocimientos sobre el funcionamiento de la tecnología actual, ¿cómo los valoraría usted en una escala del 1 al 7 ( $1=$ ningún conocimiento, $7=$ buen conocimiento)?», la mayoría de la población se colocó en las posiciones inferiores, escaso o ningún conocimiento de la escala, tal como se puede observar en los resultados que se incluyen en la tabla 4 .

\section{TABLA 4}

Valoración de los conocimientos sobre el funcionamiento de la tecnologia actual que posee la población

\begin{tabular}{ccccccccccc}
\hline \multicolumn{10}{c}{ Escala de conocimientos } \\
\hline Ningún conocimiento \\
\hline
\end{tabular}


Si se considera que un nivel aceptable de conocimientos se revela a partir de la posición 5 en la escala, entonces sólo un 12 por 100 de la población (posiciones 5 al 7) se considera en posesión de tales conocimientos, mientras que un amplio 55 por 100 manifiesta tener escaso o ningún conocimiento sobre la tecnología (posiciones 1 al 3). No deja de ser interesante constatar que la población alemana revela una distribución del grado de conocimiento de la tecnología, muy similar al que revelan los anteriores resultados. Agrupando los mismos en tres categorías o niveles —alto, medio y bajo-, las distribuciones comparativas se ordenan del modo que aparece en la tabla 5 .

\section{TABLA 5}

Comparación del nivel de conocimientos personales sobre el funcionamiento de la tecnología que manifiestan tener la población española y la población alemana

\begin{tabular}{|c|c|c|}
\hline Nivel de conocimientos sobre la tecnología & $\begin{array}{l}\text { Población } \\
\text { española }\end{array}$ & $\begin{array}{l}\text { Población } \\
\text { alemana }\end{array}$ \\
\hline 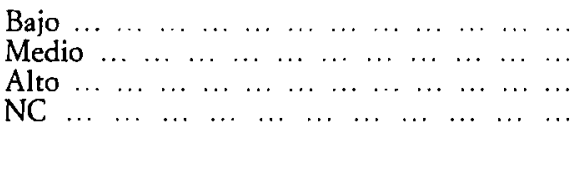 & $\begin{array}{c}55 \\
14 \\
12 \\
19 \\
(1.196)\end{array}$ & $\begin{array}{c}50 \\
18 \\
18 \\
14 \\
(2.000)\end{array}$ \\
\hline
\end{tabular}

Las diferencias entre los niveles de conocimiento de la población española y de la población alemana son moderadas. Sólo un 5 por 100 menos de alemanes que de españoles que manifiestan tener escasos conocimientos sobre tecnología, y un 6 por 100 más de alemanes que de españoles que manifiestan tener unos buenos conocimientos sóbre táles temas. Pero en 'ímeás gentirales la pauta distributiva es identica: alrededor de la mitad dé lá pob́ación con conocimientos escasos o nulos. $y$ el resto se divide en partes casi iguales entre la población que so responde -y que eventualmente se quede incor-

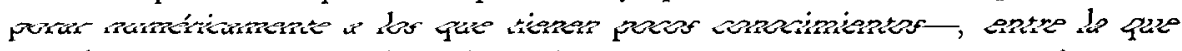
manifiesta tener un nivel medio y la que tiene un conocimiento suficiente.

Tal como cabía esperar, existen grandes diferencias sociodemográficas entre la población con un nivel alto de conocimientos sobre la tecnología y aquella otra población que manifiesta niveles bajos. El grupo minoritario de población con conocimientos altos está integrado, sobre todo, por varones de edades inferiores a 40 años, residentes en ciudades, con niveles medios y 
altos de estudios formales y profesionales y cuyas preferencias ideológicas son muy diversas. Por el contrario, el grupo mayoritario de población con pobres conocimientos de tecnología está integrado preferentemente por hombres y mujeres de edades medias y altas, residentes en ciudades pequeñas o medianas y en pueblos rurales, con niveles de estudios primarios o menos de primarios y que o bien se dedican a sus labores o bien a trabajos escasos cualificados.

Tal como cabía esperar, la relación entre grado de conocimiento de la tecnología y el grado de confianza en la misma es claramente positiva, de tal manera que a mayor conocimiento más alta es la confianza:

\begin{tabular}{|c|c|c|c|}
\hline \multirow[b]{2}{*}{ Grado de contianza en la tecnologia } & \multicolumn{3}{|c|}{$\begin{array}{l}\text { NIVEL DE CONOCIMIENTOS } \\
\text { SOBRE TECNOLOGIA }\end{array}$} \\
\hline & Bajo & Medio & Alto \\
\hline $\begin{array}{llllllllll}\text { Escepticismo } & \ldots & \ldots & \ldots & \ldots & \ldots & \ldots & \ldots & \ldots \\
\text { Neutral } & \ldots & \ldots & \ldots & \ldots & \ldots & \ldots & \ldots & \ldots & \ldots \\
\text { Aprobación } & \ldots & \ldots & \ldots & \ldots & \ldots & \ldots & \ldots & \ldots\end{array}$ & $\begin{array}{l}21 \\
28 \\
44\end{array}$ & $\begin{array}{l}10 \\
40 \\
50\end{array}$ & $\begin{array}{l}10 \\
11 \\
77\end{array}$ \\
\hline
\end{tabular}

Mientras que el 77 por 100 de los que manifiestan tener un elevado conocimiento sobre el funcionamiento de la tecnología confian en la capacidad de la tecnología para resolver los problemas de la Humanidad, tal porcentaje desciende significativamente al 44 por 100 entre los que tienen un pobre nivel de conocimientos. Son resultados que señalan claramente la necesidad de que la población eleve sus conocimientos generales sobre la ciencia y la tecnología para que las acepte de mejor grado. Dado que los resultados obtenidos en el estudio alemán son prácticamente idénticos a los de nuestro estudio, ello parece indicar que nos encontramos ante una pauta general en las sociedades de relación positiva y directa entre nivel de conocimientos de la población y aceptación de la ciencia y tecnología.

\section{PAPEL SOCIAL DE LOS CIENTIFICOS}

Del estudio de la imagen generalizada de la ciencia, en abstracto, vamos a pasar ahora al estudio de la imagen que tiene tanto la población general como los diputados del papel social que representan los científicos en el mundo actual. Y ello lo vamos a hacer a través del análisis del grado de acuerdo manifestado por los entrevistados a dos proposiciones que contienen sendos juicios de valor acerca del comportamiento de los científicos. 
La primera proposición recoge la idea de que «los investigadores científicos, por sus conocimientos, poseen un poder que puede convertirlos en peligrosos», mientras que la segunda proposición contiene la idea de que «los investigadores científicos son gentes entregadas que trabajan para el bien de la Humanidad». Es decir, la contraposición de la «imagen conspiratoria» versus la «imagen altruista» de los científicos.

Pues bien, los resultados obtenidos, que se contienen en la tabla 6, ponen de manifiesto el predominio de la imagen altruista de los científicos, tanto entre la población general como entre los diputados, aunque con notables diferencias entre ambas poblaciones.

\section{TABLA 6}

Opinión sobre el papel social de los cientíticos

Opiniones sobre los científicos

A) Los investigadores científicos son gentes entregadas que trabajan para el bien de la Humanidad:

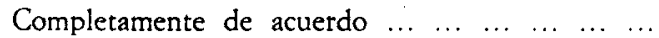

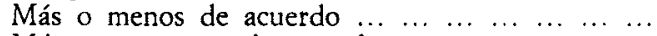

Más o menos en desacuerdo $\ldots \begin{array}{lllllll}\ldots & \ldots & \ldots & \ldots & \ldots & \ldots\end{array}$

Completamente en desacuerdo $\ldots \ldots$...

$\begin{array}{lllllllllllllll}\mathrm{NC} & \ldots & \ldots & \ldots & \ldots & \ldots & \ldots & \ldots & \ldots & \ldots & \ldots & \ldots & \ldots & \ldots\end{array}$

B) Los investigadores científicos, por sus conocimientos, poseen un poder que puede convertirlos en peligrosos:

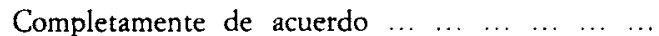

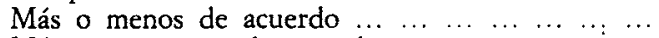

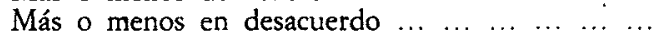

Completamente en desacuerdo

NC .

\section{Población \\ general}

Diputados

$\begin{array}{rr}29 & 29 \\ 38 & 69 \\ 13 & 11 \\ 2 & - \\ 18 & -\end{array}$

29

11

二 
do, y otro 32 por 100 más o menos de acuerdo, con dicha idea de la peligrosidad de los científicos, mientras que los diputados que así se manifiestan tan sólo representan el 6 y el 17 por 100 , respectivamente.

Por otro lado, el 89 por 100 de los diputados se manifiesta con un mayor y menor grado de acuerdo con la «imagen altruista» de los científicos, mientras que así lo hace el 67 por 100 de la población general. Además, cabe destacar la mayor coherencia del punto de vista de los diputados, quienes reconocen mayoritariamente el papel positivo del trabajo de los investigadores científicos, al mismo tiempo que rechazan, también mayoritariamente, la idea de la pretendida peligrosidad de tales investigadores. Sin embargo, y tal como se ha visto anteriormente, la población general pone de manifiesto una cierta dosis de incoherencia al aceptar, con una mayoría menor que en el caso de los diputados, el papel positivo del trabajo de los científicos, al mismo tiempo que más de la mitad de dicha población acepta, igualmente, la idea de la peligrosidad de los mismos.

Tales diferencias adquieren nuevos matices cuando se analiza con mayor detalle la composición de ambas poblaciones. Así, entre los diputados de UCD, PSOE y resto de partidos, se observan diferencias que bien pueden calificarse de significativas:

\begin{tabular}{|c|c|c|}
\hline Partido de los diputados & $\begin{array}{c}\text { Los cientificos, } \\
\text { por sus } \\
\text { conocimientos, } \\
\text { pueden ser } \\
\text { un peligro }\end{array}$ & $\begin{array}{c}\text { Los científicos } \\
\text { trabajan } \\
\text { para el bien } \\
\text { de la } \\
\text { Humanidad }\end{array}$ \\
\hline \multicolumn{3}{|l|}{ UCD: } \\
\hline $\begin{array}{lllllll}\text { Acuerdo } & \ldots & \ldots & \ldots & \ldots & \ldots & \ldots \\
\text { Desacuerdo } & \ldots & \ldots & \ldots & \ldots & \ldots & \ldots\end{array}$ & $\begin{array}{l}16 \\
83\end{array}$ & $\begin{array}{r}97 \\
2\end{array}$ \\
\hline \multicolumn{3}{|l|}{ PSOE: } \\
\hline $\begin{array}{lllllll}\text { Acuerdo } & \ldots & \ldots & \ldots & \ldots & \ldots & \ldots \\
\text { Desacuerdo } & \ldots & \ldots & \ldots & \ldots & \ldots & \ldots\end{array}$ & $\begin{array}{l}32 \\
67\end{array}$ & $\begin{array}{l}77 \\
23\end{array}$ \\
\hline \multicolumn{3}{|l|}{ Resto partidos: } \\
\hline $\begin{array}{llllllll}\text { Acuerdo } & \ldots & \ldots & \ldots & \ldots & \ldots & \ldots \\
\text { Desacuerdo } & \ldots & \ldots & \ldots & \ldots & \ldots & \ldots\end{array}$ & $\begin{array}{l}15 \\
85\end{array}$ & $\begin{array}{l}90 \\
10\end{array}$ \\
\hline
\end{tabular}

Como se observa en las anteriores distribuciones, el grado de rechazo de la imagen de peligrosidad de los científicos es prácticamente total entre los diputados de UCD (el 83 por 100) y los diputados del resto de los partidos (el 85 por 100), mientras que disminuye el grado de rechazo entre los diputados del PSOE, sólo el 67 por 100. Inversamente, la aceptación de la idea 
altruista del trabajo de los científicos está casi totalmente generalizada entre los diputados de UCD (el 97 por 100) y del resto de los partidos (el 90 por 100), mientras que baja significativamente entre los diputados del PSOE (el 77 por 100).

Cuando se tiene en cuenta la ocupación en la vida privada de los diputados las diferencias que se observan son menores:

\begin{tabular}{|c|c|c|}
\hline Ocupación de los diputados & $\begin{array}{c}\text { Los cientificos, } \\
\text { por sus } \\
\text { conocimientos, } \\
\text { pueden ser } \\
\text { un peligro }\end{array}$ & $\begin{array}{c}\text { Los cientificos } \\
\text { trabajan } \\
\text { para el bien } \\
\text { de la } \\
\text { Humanidad }\end{array}$ \\
\hline \multicolumn{3}{|l|}{ Docentes: } \\
\hline $\begin{array}{lllllll}\text { Acuerdo } & \ldots & \ldots & \ldots & \ldots & \ldots & \ldots \\
\text { Desacuerdo } & \ldots & \ldots & \ldots & \ldots & \ldots & \ldots\end{array}$ & $\begin{array}{l}19 \\
81\end{array}$ & $\begin{array}{l}86 \\
14\end{array}$ \\
\hline \multicolumn{3}{|l|}{ Abogados: } \\
\hline $\begin{array}{lllllll}\text { Acuerdo } & \ldots & \ldots & \ldots & \ldots & \ldots & \ldots \\
\text { Desacuerdo } & \ldots & \ldots & \ldots & \ldots & \ldots & \ldots\end{array}$ & $\begin{array}{l}30 \\
70\end{array}$ & $\begin{array}{l}90 \\
10\end{array}$ \\
\hline \multicolumn{3}{|l|}{ Profesionales: } \\
\hline $\begin{array}{lllllll}\text { Acuerdo } & \ldots & \ldots & \ldots & \ldots & \ldots & \ldots \\
\text { Desacuerdo } & \ldots & \ldots & \ldots & \ldots & \ldots & \ldots\end{array}$ & $\begin{array}{l}13 \\
87\end{array}$ & $\begin{array}{r}91 \\
9\end{array}$ \\
\hline \multicolumn{3}{|l|}{ Otras ocupaciones: } \\
\hline $\begin{array}{lllllll}\text { Acuerdo } & \ldots & \ldots & \ldots & \ldots & \ldots & \ldots \\
\text { Desacuerdo } & \ldots & \ldots & \ldots & \ldots & \ldots & \ldots\end{array}$ & $\begin{array}{l}25 \\
75\end{array}$ & $\begin{array}{l}89 \\
11\end{array}$ \\
\hline
\end{tabular}

La ocupación de los diputados apenas discrimina en la distribución porcentual de la opinión de que los científicos trabajan para el bien de la $\mathrm{Hu}$ manidad, ya que el grado de acuerdo con dicha afirmación gira alrededor del 90 por 100 para los cuatro grupos ocupacionales considerados. Sin embargo, sí se observan diferencias de cierta significación al considerar el grado de acuerdo en relación a la eventual peligrosidad de los científicos, ya que, en este caso, hasta un 30 por 100 de los diputados que son abogados manifiestan su acuerdo, mientras que entre los diputados que son docentes o profesionales dicho porcentaje se encuentra por debajo del 20 por 100 . Todos estos datos inciden en el resultado ya anteriormente expuesto de que la variable ideológica desempeña un papel relevante y primordial en la determinación de las actitudes hacia la ciencia y la tecnología, y esto es así tanto para la población general como para los diputados.

En efecto, al realizar el análisis de la distribución de la imagen «altruista» y de la imagen «conspiratoria» de los científicos entre la población general 
se observa la misma pauta que para el caso de los diputados; es decir, la población identificada con posiciones de izquierda manifiesta mayor grado de acuerdo (el 61 por 100) con la idea de la peligrosidad de los científicos que la población cercana a posturas de centro y derecha (el 48 por 100). Del mismo modo, el grado de acuerdo con la idea del carácter beneficioso de los científicos es menor entre la población de izquierdas (el 55 por 100) que entre la población de derechas (el 74 por 100). Se trata de diferencias porcentuales que no se observan al considerar otras variables relevantes, tales como nivel de estudios, ocupación, edad, sexo o lugar de residencia. De todos modos, hay que señalar que a mayor nivel de estudios de la población, más elevado es el grado de acuerdo con la imagen altruista de los científicos y mayor es el grado de desacuerdo con la imagen conspiratoria.

Incidiendo en el tema del papel social de los científicos, se realizó otra pregunta a los entrevistados en los siguientes términos: «Visto en conjunto, ¿cree usted que los científicos hacen más daño que beneficio a la Humanidad, más beneficio que daño o, aproximadamente, igual de daño que de beneficio?» De este modo, se trataba de sintetizar en un solo indicador la imagen global del trabajo de los científicos. Los resultados obtenidos revelan, una vez más, el predominio casi absoluto de la imagen positiva de la ciencia que manifiestan los diputados y la división de opiniones que existe entre la población general (tabla 7).

\section{TABLA 7}

Opinión sobre el beneficio o daño que bacen a la Humanidad los cientíticos

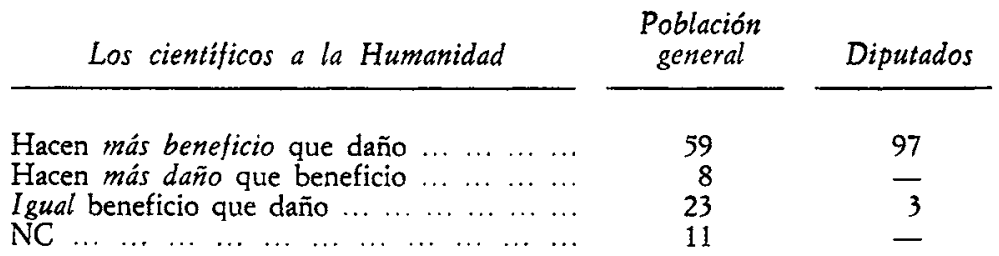

(1.196)

(106)

El 97 por 100 de los diputados considera que los científicos hacen más beneficio que daño a la Humanidad, mientras que la población que así piensa no sobrepasa el 59 por 100 . Ningún diputado considera que los científicos hagan más daño que beneficio a la Humanidad, pero así lo piensa un pequeno, pero significativo, grupo de población (el 8 por 100), mientras que la 
idea de que el balance final del beneficio y del daño que realizan los científicos está equilibrado la apoya el 23 por 100 de la población general y el 3 por 100 de los diputados.

Ahora bien, este pequeño grupo de diputados que considera que se reparten por igual los beneficios y los daños de la ciencia está formado íntegramente por diputados de izquierda, en concreto del PSOE y del PCE, ya que los diputados de UCD y AP, en su totalidad, se identifican con la idea de que los beneficios son mayores que los daños.

No ocurre así con la población general, que manifiesta un grado de heterogeneidad en sus actitudes hacia los científicos mayor que la que muestran los diputados. De nuevo las variables influyentes en la determinación de la percepción de las consecuencias del trabajo de los científicos son la ideología y el nivel de conocimientos. Por lo que se refiere a la variable ideológica, su funcionamiento sigue la misma pauta ya observada con anterioridad: así, sólo el 59 por 100 de los entrevistados de izquierda considera que los científicos hacen más beneficio que daño, mientras que entre los que se sitúan en el centro del espectro político dicho porcentaje se eleva al 73 por 100 . De todos modos, el 4 por 100 de las personas de centro que considera que los científicos hacen más daño que beneficio y el 15 por 100 que estima que hacen igual beneficio que daño son datos que ponen de manifiesto que, aunque minoritaria, la imagen crítica y negativa de la ciencia ha llegado a penetrar con cierta profundidad en la consciencia colectiva y social.

En cuanto al nivel de conocimientos que posee la población acerca del funcionamiento de la tecnología, también influye en la consideración del trabajo científico, de tal modo que a mayor nivel de conocimiento, mayor es el reconocimiento del carácter beneficioso de dicho trabajo, tal como se observa en la tabla 8 .

\section{TABLA 8}

Opinión sobre el beneficio o daño que hacen a la Humanidad los cientificos, según el nivel de conocimientos tecnológicos de la población

NIVEL DE CONOCIMIENTOS

Los científicos a la Humanidad

\begin{tabular}{|c|c|c|c|}
\hline Poco & Regular & Bueno & $N C$ \\
\hline 58 & 56 & 77 & 51 \\
\hline 10 & 6 & 3 & 5 \\
\hline 25 & 35 & 18 & 11 \\
\hline 7 & 4 & 2 & 32 \\
\hline
\end{tabular}


Más de las tres cuartas partes de las personas que manifiestan tener un buen nivel de conocimientos tecnológicos reconocen la parte beneficiosa del trabajo del científico, mientras que sólo alcanza al 58 por 100 de los que tienen pocos conocimientos los que afirman tal reconocimiento. $\mathrm{E}$, inversamente, mientras que sólo un reducido 3 por 100 de las personas que tienen buenos conocimientos científicos considera que los científicos hacen más daño que beneficio, tal porcentaje se eleva al 10 por 100 entre los que manifiestan tener escasos o nulos conocimientos al respecto.

\subsection{Influencia de la opinión de los científicos en la construcción de una central nuclear}

Antes de analizar los resultados concretos referentes al grado de influencia de la opinión de los científicos en la construcción de una central nuclear, vamos a detenernos en el estudio del grado de confianza general que tiene el público en las personas que dirigen la comunidad de investigadores científicos y otras instituciones básicas de la sociedad. La pregunta se formuló del siguiente modo: "¿Qué grado de confianza tiene usted en las personas que dirigen las instituciones siguientes: comunidad de investigadores científicos, ejército, educación, Gobierno, grandes empresas y Congreso de Diputados?" De lo que se trata con este indicador es de establecer un marco comparativo entre el grado de confianza que provocan los científicos y el que inducen otras instituciones sociales. Los resultados obtenidos se resumen en la tabla 9.

\section{TABLA 9}

Grado de confianza de la población en las personas que dirigen diversas instituciones

\begin{tabular}{|c|c|c|c|c|c|c|}
\hline \multirow[b]{2}{*}{ Instituciones } & \multicolumn{6}{|c|}{ GRADO DE CONFIANZA } \\
\hline & 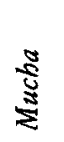 & 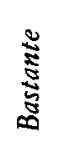 & 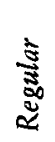 & $\underset{8}{8}$ & $\begin{array}{l}\mathbb{Z} \\
\mathbb{8} \\
\text { S }\end{array}$ & $\mathcal{Z}$ \\
\hline Comunidad de investigadores científicos. & 10 & 22 & 21 & 5 & 4 & 8 \\
\hline $\begin{array}{llllllllll}\text { Ejército } & \ldots & \ldots & \ldots & \ldots & \ldots & \ldots & \ldots & \ldots & \ldots\end{array}$ & 11 & 22 & 25 & 10 & 10 & 22 \\
\hline $\begin{array}{lllllllllll}\text { Educación } & \ldots & \ldots & \ldots & \ldots & \ldots & \ldots & \ldots & \ldots & \ldots\end{array}$ & 11 & 26 & 26 & 12 & 5 & 19 \\
\hline $\begin{array}{lllllllllll}\text { Gobierno } & \ldots & \ldots & \ldots & \ldots & \ldots & \ldots & \ldots & \ldots & \ldots\end{array}$ & 5 & 15 & 32 & 17 & 13 & 19 \\
\hline $\begin{array}{lllllll}\text { Grandes empresas } & \ldots & \ldots & \ldots & \ldots & \ldots & \ldots\end{array}$ & 5 & 16 & 26 & 18 & 12 & 24 \\
\hline Congreso de Diputados $\ldots \ldots \ldots \ldots \ldots$ & 4 & 15 & 29 & 17 & 12 & 23 \\
\hline
\end{tabular}


Las personas que dirigen la comunidad de investigadores científicos, el ejército y el sistema educativo merecen un elevado y parecido grado de confianza a la población, mientras que el Gobierno, las grandes empresas y el Congreso de los Diputados son dirigidos por personas que provocan un menor grado de confianza. Pero es que, además, la comunidad de investigadores científicos, y las personas que la dirigen, producen el menor nivel de desconfianza, sólo el 9 por 100 ( 5 por 100 poca desconfianza y 4 por 100 muy poca desconfianza), mientras que el ejército (con el 20 por 100) y el sistema educativo (con el 17 por 100) sobrepasan a este respecto a los científicos.

Visto el relativamente alto grado de confianza que concitan los científicos, vamos a analizar ahora si se mantiene dicha confianza en una situación concreta, como es la eventual recomendación para que se construyera una central nuclear. La pregunta se formuló en los siguientes términos: «Supongamos que se discute sobre la construcción de una central atómica para la producción de electricidad y que los investigadores científicos afirman que ésta no representa ningún peligro, ¿ piensa usted que se puede construir con completa confianza, con más o menos confianza, con más o menos desconfianza, con completa desconfianza?» Las respuestas obtenidas, tanto para la población general como para los diputados, se contienen en la tabla 10.

\section{TABLA 10}

Grado de confianza que se puede otorgar a unos científicos que afirman que la construcción de una central atómica para la producción de electricidad no ofrece peligro alguno

\begin{tabular}{|c|c|c|}
\hline $\begin{array}{c}\text { Grado de confianza en la opinión } \\
\text { de los científicos }\end{array}$ & $\begin{array}{l}\text { Población } \\
\text { general }\end{array}$ & Diputados \\
\hline 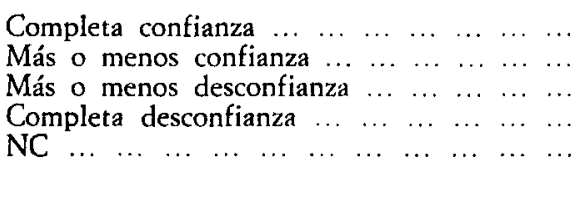 & $\begin{array}{c}13 \\
24 \\
26 \\
19 \\
18 \\
(1.196)\end{array}$ & $\begin{array}{r}24 \\
60 \\
12 \\
4 \\
- \\
(106)\end{array}$ \\
\hline
\end{tabular}

Una primera lectura de los resultados obtenidos revela que los diputados, en conjunto, muestran un elevado grado de confianza en las recomendaciones de los científicos, mientras que la población se divide en dos grupos: el de los confiados y el de los desconfiados, siendo estos últimos ligeramente más numerosos que los primeros. 
En efecto, el 24 por 100 de los diputados otorgaría completa confianza a las recomendaciones de los científicos y otro 60 por 100 le otorgaría una confianza menor. Sólo un 4 por 100 mantendría su completa desconfianza y otro 12 por 100 desconfiaría en menor grado. Ahora bien, la distribución de tales opiniones varía significativamente cuando se considera el partido de pertenencia y la ocupación de origen. Si nos fijamos tan sólo en los porcentajes de confianza y desconfianza completas, las diferencias se evidencian por sí mismas:

\begin{tabular}{|c|c|c|}
\hline & $\begin{array}{l}\text { Completa } \\
\text { confianza } \\
\text { opinión } \\
\text { científicos } \\
(\%)\end{array}$ & $\begin{array}{c}\text { Completa } \\
\text { desconfianza } \\
\text { opinión } \\
\text { cientificos } \\
(\%)\end{array}$ \\
\hline \multicolumn{3}{|l|}{ Ocupación: } \\
\hline 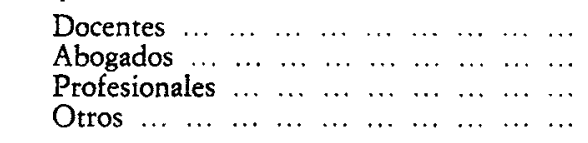 & $\begin{array}{l}34 \\
20 \\
31 \\
18\end{array}$ & $\begin{array}{r}5 \\
10 \\
9 \\
18\end{array}$ \\
\hline \multicolumn{3}{|l|}{ Partido político: } \\
\hline $\begin{array}{lllllllllll}\operatorname{UCD} & \ldots & \ldots & \ldots & \ldots & \ldots & \ldots & \ldots & \ldots & \ldots & \ldots \\
\operatorname{PSOE} & \ldots & \ldots & \ldots & \ldots & \ldots & \ldots & \ldots & \ldots & \ldots & \ldots \\
\operatorname{Otros} & \ldots & \ldots & \ldots & \ldots & \ldots & \ldots & \ldots & \ldots & \ldots & \ldots\end{array}$ & $\begin{array}{r}38 \\
5 \\
30\end{array}$ & $\begin{array}{r}2 \\
28 \\
5\end{array}$ \\
\hline
\end{tabular}

El grado máximo de confianza en los científicos lo manifiestan los diputados que o bien son docentes o bien ejercen una profesión liberal, y que pertenecen a partidos de centro o derecha. Por el contrario, el grado máximo de desconfianza lo manifiestan los diputados que son abogados o que tienen ocupaciones de rango medio o medio bajo, y que están vinculados a partidos de izquierda. Se trata de perfiles que son congruentes con los resultados hasta ahora obtenidos.

Algo similar ocurre con las características sociodemográficas que caracterizan a los dos grupos de población que manifiestan confiar, o desconfiar, de la opinión de los científicos: la preferencia ideológica y el status social, tal como viene determinado por la ocupación que se desempeña, son las dos variables que discriminan acusadamente a los dos grupos de confiados y desconfiados. Así, entre los votantes del PCE, tan sólo un 28 por 100 confiaría en las recomendaciones de los científicos y un mayoritario 63 por 100 desconfiaría de las mismas. Sin embargo, entre los votantes de AP los porcentajes respectivos invierten prácticamente su cuantía, ya que asciende al 59 por 100 el porcentaje de confiados y desciende al 27 por 100 el de los desconfiados. 
Cosa parecida ocurre con la profesión que se desempeña, ya que las diferencias que separan a los profesionales superiores de los no cualificados y parados son del orden de las 20 unidades porcentuales en el sentido de mostrar más confianza las personas que desempeñan trabajos altamente cualificados. Sin embargo, ni la edad, ni el sexo o el lugar de residencia descriminan tan fuertemente las distribuciones de las opiniones, porque, tal como se está viendo, las opiniones y las actitudes hacia las actividades y el mundo que configuran la ciencia y la tecnología vienen determinadas en buena medida por el nivel de conocimientos y la ideología de los individuos.

De todos modos, conviene destacar que, frente a la mayoritaria confianza que depositan los diputados en las recomendaciones de los científicos en tema tan controvertido como es el de la construcción de una central nuclear -unanimidad que disminuye significativamente entre los diputados de izquierda-, la población general se manifiesta muy sensibilizada ante el referido evento, de tal suerte que, incluso entre las personas que tienen un buen nivel de conocimientos del funcionamiento de la tecnología, se destaca un grupo cuantitativamente importante de desconfiados (véase tabla 11).

\section{TABLA 11}

Grado de confianza en las recomendaciones de los cientificos para que se construya una central nuclear, según el nivel de conocimientos tecnológicos de la población

\begin{tabular}{|c|c|c|c|c|}
\hline \multirow[b]{2}{*}{ Grado de contianza } & \multicolumn{4}{|c|}{ NIVEL DE CONOCIMIENTOS TECNOLOGICOS } \\
\hline & Poco & Regular & Bueno & $N C$ \\
\hline 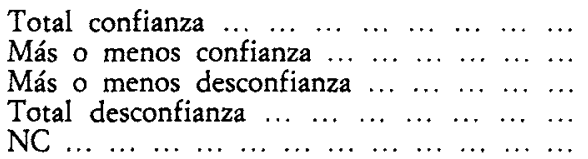 & $\begin{array}{l}13 \\
24 \\
29 \\
23 \\
12\end{array}$ & $\begin{array}{r}14 \\
32 \\
31 \\
20 \\
2\end{array}$ & $\begin{array}{r}20 \\
36 \\
23 \\
15 \\
6\end{array}$ & $\begin{array}{r}9 \\
13 \\
17 \\
10 \\
51\end{array}$ \\
\hline
\end{tabular}

La distribución de resultados que se contiene en la tabla 12 muestra con toda claridad la relación directa entre nivel de conocimientos y grado de confianza, pero la potencial conflictividad de la construcción de centrales nucleares se revela en ese 38 por 100 de población que, pese a manifestar tener un buen nivel de conocimientos tecnológicos, continúa desconfiando de las recomendaciones de los científicos. En todo caso, el carácter dependiente y directo de la variación de ambas variables es una prueba de que, a largo plazo y en términos generales, resulta positivo incrementar los conocimientos 
tecnológicos de la población para que se acepten mejor las innovaciones tecnológicas y el cambio científico..

\section{AVANCE TECNOLOGICO Y PARO}

Una constante de los procesos de innovación tecnológica, desde que se iniciara la etapa industrial de la historia de la Humanidad, es el incremento a corto plazo del paro, más o menos sectorial, más o menos generalizado. También es cierto que a largo plazo, y por lo que la historia pasada nos muestra, los procesos de innovación tecnológica, una vez consolidados, generan mayor riqueza y una disminución del paro. Pero este último hecho suele servir de poco consuelo, caso de que se conozca suficientemente, a las personas que pierden su puesto de trabajo al caer en la obsolescencia no productiva las empresas en las que desempeñaban su profesión.

Todo parece indicar que a finales del siglo $\mathrm{xx}$ las sociedades occidentales, incluida naturalmente España, están sometidas a un proceso de cambio tecnológico muy intenso que viene acompañado de un incremento preocupante del paro. La opinión pública, en consecuencia, aparece muy sensibilizada ante este tema, de ahí que en el presente estudio sea mayoritaria la población que admite la existencia de una relación positiva entre progreso técnico y paro. En efecto, ante la siguiente pregunta: "Algunos afirman que el progreso técnico conduce al paro; usted, personalmente, ¿cuán de acuerdo está con dicha opinión?", las respuestas apuntan mayoritariamente en la dirección de estar de acuerdo (véase tabla 12).

TABLA 12

Grado de acuerdo con la opinión de que el progreso técnico conduce al paro

El progreso técnico conduce al paro

Completamente de acuerdo

Más o menos de acuerdo

Mas o menos en desacuerdo $\ldots \ldots \ldots$........

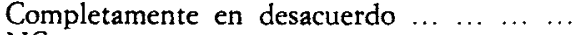

NC

\begin{tabular}{c}
$\begin{array}{c}\text { Poblacion } \\
\text { general }\end{array} \quad$ Diputados \\
\hline
\end{tabular}

24

33

43

15

(108)

(1.196) 
De nuevo nos encontramos con las diferencias ciertamente importantes de las opiniones de los diputados y de las que manifiesta la población general. Ningún diputado está completamente de acuerdo con la idea de la relación directa entre progreso técnico y paro, aunque una cuarta parte de dicho colectivo manifiesta un cierto grado de acuerdo con la misma; pero la mayoría, en concreto las tres cuartas partes de los diputados, está en desacuerdo con dicha idea. Quizá el hábito de contemplar los fenómenos del cambio social en su adecuada perspectiva histórica ha contribuido a que los diputados nieguen mayoritariamente la relación directa entre progreso técnico y paro.

No obstante, la población general no comparte la opinión de la mayoría de los diputados. Un 37 por 100 de las personas entrevistadas está completamente de acuerdo con la idea de responsabilizar al progreso técnico del paro y otro 31 por 100 manifiesta estar más o menos de acuerdo. Sólo un 17 por 100 de la población está en desacuerdo con dicha idea y de acuerdo, por tanto, con la opinión de la mayoría de los diputados.

En esta opinión, el elemento ideológico desempeña un papel menos relevante que en las opiniones vistas hasta ahora, y, en cambio, desempeña un papel más importante el nivel de estudios y el tipo de ocupación. Así, la distribución de las opiniones entre los diputados de UCD y del PSOE es idéntica -25 por 100 de acuerdo, 75 por 100 de desacuerdo--, mientras que los diputados que en su profesión privada ejercen como docentes sólo un minoritario 5 por 100 está de acuerdo y un significativo 95 por 100 en desacuerdo, frente al 35 por 100 de diputados abogados que sí creen que el progreso técnico provoca el paro.

Con la población general ocurre algo parecido, siendo los cuadros superiores y los profesionales independientes los que en mayor medida rechazan la relación progreso técnico-paro, mientras que los parados, los empresarios y los obreros se muestran mayoritariamente de acuerdo con dicha ider.

Con el fin de analizar con mayor detalle la opinión existente acerca del impacto del progreso técnico en el mundo del trabajo, vamos a estudiar las respuestas dadas a una pregunta más compleja que la anterior, pregunta que, además, también fue formulada al público alemán en el estudio anteriormente citado, lo que nos va a permitir de nuevo realizar un análisis comparativo más completo.

La pregunta se formuló en los siguientes términos: «En los últimos años, en muchos lugares de trabajo se han introducido nuevas máquinas, aparatos y métodos de trabajo que son tecnológicamente más avanzados que los anteriores. En relación a su empresa, ¿podría usted decirme si ha ocurrido algo de lo siguiente?», y a continuación se leían una serie de consecuencias hipotéticas, tales como hacer el trabajo más fácil, más seguro, más interesante, provocar desempleo, etc. Las respuestas obtenidas se han distribuido del siguiente modo (tabla 13): 
TABLA 13

Efectos que ba tenido la introducción de nueva tecnología en las empresas

Considero que la nueva tecnología introducida en mi empresa

\begin{tabular}{|c|c|c|}
\hline $\begin{array}{l}\text { Población } \\
\text { española }\end{array}$ & $\begin{array}{l}\text { Población } \\
\text { alemana }\end{array}$ & Diputados \\
\hline $\begin{array}{l}66 \\
49 \\
50\end{array}$ & $\begin{array}{l}81 \\
47 \\
41\end{array}$ & $\begin{array}{l}82 \\
69 \\
39\end{array}$ \\
\hline $\begin{array}{l}36 \\
23 \\
43 \\
25 \\
11\end{array}$ & $\begin{array}{l}44 \\
37 \\
27 \\
26 \\
15\end{array}$ & $\begin{array}{l}37 \\
21 \\
62 \\
35 \\
19\end{array}$ \\
\hline 14 & 10 & 25 \\
\hline
\end{tabular}

Ha hecho el trabajo más fácil

Ha hecho el trabajo más seguro ....

Ha hecho el trabajo más seguro ... ...

Ha provocado desempleo $\ldots \ldots \ldots \ldots \ldots$

Ha hecho que el trabajo sea más monó

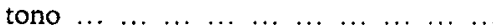

$\mathrm{Ha}$ hecho el trabajo más duro $\ldots . . . . .$.

$\mathrm{Ha}$ aliviado de la rutina $\ldots \ldots \ldots \ldots \ldots$

$\mathrm{Ha}$ hecho el trabajo más interesante ...

Ha ereado nuevos puestos de irabajo....

$\mathrm{Ha}$ asegurado los actuales puestos de trabajo

La semejanza de los resultados obtenidos parece indicar que la introducción de nueva tecnología en las empresas suele producir efectos universales, casi con independencia del tipo de empresa y del nivel de cualificación de la persona que percibe el cambio. Vamos a matizar ahora la anterior afirmación ciñéndonos al detalle de los resultados concretos.

El mayor grado de acuerdo y unanimidad se refiere al hecho de que la nueva tecnología hace más fácil el trabajo. En ello está de acuerdo el 66 por 100 de la población española, el 81 por 100 de la población alemana y el 82 por 100 de los diputados. Por otro lado, el menor grado de acuerdo que unánimemente manifiestan los tres grupos de población entrevistados se produce al tratar de relacionar la introducción de nueva tecnología con la creación de nuevos puestos de trabajo. Sólo un 11 por 100 de la población española, el 15 por 100 de la población alemana y el 19 por 100 de los diputados consideran que se producen tales efectos. Por el contrario, más de la mitad de los integrantes de tales grupos manifiestan su desacuerdo al respecto; es decir, consideran que la introducción de nueva tecnología no ha ayudado a crear nuevos puestos de trabajo.

Los porcentajes de respuestas positivas son mayores que el de respuestas negativas para las siguientes consecuencias: el trabajo se ha hecho más seguro - en el sentido de que han disminuido los riesgos de accidentes-; el trabajo se ha hecho más monótono - es el efecto de la rutinización que introducen muchas máquinas-; se han aliviado muchas tareas mentales rutinarias, y se ha provocado mayor desempleo. Por otro lado, los porcentajes de respuestas negativas son mayores que el de las positivas; es decir, que hay más gente que considera que las cosas han funcionado realmente en sentido contrario para las siguientes consecuencias: ha hecho el trabajo más duro, ha hecho el 
trabajo más interesante, ha creado nuevos puestos de trabajo y ha asegurado los actuales puestos de trabajo.

Así, pues, cabe concluir que las personas perciben las consecuencias de la introducción de nuevas tecnologías en sus respectivas empresas con sentimientos encontrados, quizá porque las consecuencias objetivas de tales cambios son también contradictorios. De todos modos, la situación profesional y ocupacional de los entrevistados condiciona fuertemente la percepción de tales consecuencias. Los empresarios, profesionales y cuadros superiores y medios tienden a ver más aspectos positivos en la introducción de nueva tecnología que los obreros poco o medianamente cualificados. Igualmente, los diputados que en sus vidas privadas son profesionales son más receptivos a las nuevas tecnologías que los diputados que son profesores o abogados.

\section{LA CIENCIA EN ESPAÑA}

En las páginas anteriores hemos analizado aspectos más o menos concretos de la ciencia y de la tecnología, pero sin referirlos a ninguna sociedad en concreto. Ahora vamos a ocuparnos de analizar algunos aspectos de la situación de la ciencia en España y de los científicos españoles.

La opinión que la población y los diputados tienen del grado de importancia que le concede la sociedad española a la investigación española es bastante pobre. Ante la siguiente pregunta: « ¿Cree usted que al ciudadano medio español le importa el número, volumen y calidad de la investigación científica en España?», las respuestas tienden a decantarse del lado negativo, sobre todo entre los diputados, tal como se observa en los resultados que se incluyen en la tabla 14.

\section{TABLA 14}

Opinión sobre la importancia que le concede el ciudadano medio español a la investigación científica

Al ciudadano le importa la cantidad y calidad de la investigación cientifica en España

$\begin{array}{llllllllllllll} & \text { Sí } & \ldots & \ldots & \ldots & \ldots & \ldots & \ldots & \ldots & \ldots & \ldots & \ldots & \ldots & \ldots\end{array}$

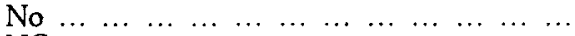

$\begin{array}{llllllllllll}N C & \ldots & \ldots & \ldots & \ldots & \ldots & \ldots & \ldots & \ldots & \ldots & \ldots & \ldots\end{array}$

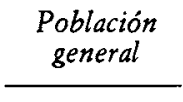

Diputados

$\begin{array}{cr}25 & 19 \\ 54 & 81 \\ 20 & - \\ (1.196) & (108)\end{array}$


Más del 50 por 100 de la población general y un poco más del 80 por 100 de los diputados consideran que a los ciudadanos españoles no les preocupa la investigación científica que se realiza en España. Esta actitud crítica se refuerza entre las personas que tienen niveles de estudios superiores y que se encuentran próximas a posiciones ideológicas de izquierda, y entre los diputados que se dedican a la docencia en sus vidas privadas. Son, pues, minotitarios los grupos españoles y los diputados que consideran que sí existe preocupación por lo científico en España.

No obstante, sí existe voluntad de que las cosas mejoren para la ciencia, como lo prueba el hecho de que un grupo muy amplio de población general y la totalidad de los diputados consideran que debiera incrementarse el gasto público en investigación. En efecto, ante la pregunta "¿Cree usted que el Gobierno debería gastar más en la investigación científica?», las respuestas tienden a concentrarse más en el lado positivo que en el negativo (véase tabla 15).

\section{TABLA 15}

Opinión sobre el incremento de gasto en la investigación científica $y$ el incremento de los impuestos

Se debería gastar más en la investigación científica

Sí, mucho más

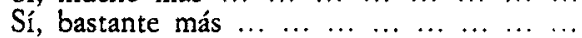

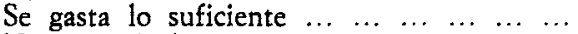

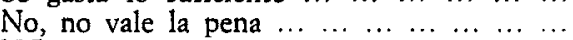

$\mathrm{NC}$

NC...

\section{Incremento del gasto en investigación aunque aumenten los impuestos}

S

No 24

19

57

\begin{tabular}{c}
$\begin{array}{c}\text { Población } \\
\text { general }\end{array}$ \\
\hline
\end{tabular}

Diputados

$\begin{array}{rl}21 & 71 \\ 27 & 29 \\ 16 & - \\ 8 & -\end{array}$

(1.196)
(108)

(574)

87

11

(108)

Los diputados son los que enfatizan con mayor fuerza sus opiniones de que el Gobierno debiera gastar más en investigación científica, lo que hace pensar que la propuesta de una ley al respecto en el Parlamento encontraría un elevado apoyo por todos los grupos parlamentarios. En efecto, el 71 por 
100 de los diputados opina que el gasto público en investigación científica debiera incrementarse «mucho más», y el restante 29 por 100 opina que debiera incrementarse «bastante más».

Entre la población general el grado de apoyo es menor, pero en términos amplios no deja de ser positivo. Así, el 48 por 100 de los entrevistados opina que debiera gastarse más en investigación, mientras que el 16 por 100 considera que los presupuestos actuales son suficientes. Sólo un minoritario 8 por 100 de los entrevistados se inclina del lado pesimista y considera que no vale la pena gastar dinero en tales menesteres. El restante 29 por 100 de población no manifiesta opinión alguna.

Además, son mayoritarios los diputados (el 87 por 100) que consideran que ese supuesto incremento del gasto público se debiera llevar adelante, aunque ello supusiese un incremento de los impuestos. La población general se muestra menos entusiasta que los diputados en recurrir al aumento de los impuestos para financiar mejor la investigación, aunque son poco numerosas las personas que se negarían a ello (sólo el 19 por 100), mientras que la mayoría (el 57 por 100) prefiere refugiarse en un no comprometido «no contesta», para no tener que opinar sobre un tema que en último término depende de la voluntad política de los gobernantes.

También se observan diferencias importantes en las opiniones de los diputados y de la población general cuando se contrastan las líneas que debieran seguir los créditos destinados a financiar diversas áreas de investigación (véase tabla 16). De las diversas áreas de investigación propuestas, esto es, salud, medio ambiente, bienes de consumo, aplicaciones civiles de la energía atómica, aeronáutica, militar y espacial, las discrepancias más notables se observan en las opiniones sobre los créditos, que debieran dirigirse a investigar aplicaciones civiles de la energía atómica.

Mientras que, mayoritariamente (el 69 por 100), los diputados consideran que sería necesario aumentarlos, sólo el 24 por 100 de la población se manifiesta en tal sentido. Una vez más encontramos que el tema nuclear provoca respuestas populares negativas, a pesar de que los representantes políticos de esta población manifiestan respuestas mayoritariamente positivas al respecto. También las áreas de investigación referidas al campo de la aeronáutica y de lo espacial provocan diferencias de opinión entre los diputados, más proclives a protegerlas, y la población, menos interesada en ellos. Las áreas de salud, medio ambiente y bienes de consumo se perfilan como las más «populares» y las que concitan mayor grado de coincidencia entre la población y sus representantes en el Parlamento ${ }^{6}$. Los anteriores resultados evidencian que nos encontramos ante problemas de imágenes públicas que se basan en estereotipos sobre lo que representa para la sociedad cada área de investigación, es-

La investigación militar provoca las mayores divisiones de opinión, tanto entre la población como entre los diputados, repartiéndose en grupos numéricamente parecidos los partidarios de aumentar, de disminuir y de no alterar los créditos de investigación. 


\section{TABLA 16}

Opinión sobre lo que seria deseable bacer con los créditos para la investigación científica en distintas áreas

\begin{tabular}{|c|c|c|c|c|c|c|c|c|}
\hline \multirow[b]{2}{*}{ Areas de investigación } & \multicolumn{2}{|c|}{ AUMENTARLOS } & \multicolumn{2}{|c|}{ DISMINUIRLOS } & \multicolumn{2}{|c|}{ DEJARLOS COMO ESTAN } & \multicolumn{2}{|c|}{ NC } \\
\hline & Poblac ón & Diputados & Población & Dipulados & Población & Diputados & Población & Diputados \\
\hline $\begin{array}{llllllll}\text { Salud } & \ldots & \ldots & \ldots & \ldots & \ldots & \ldots & \ldots\end{array}$ & 86 & 99 & 1 & - & 5 & 1 & 8 & - \\
\hline Medio ambiente $\quad \ldots \quad \ldots \quad \ldots$. & 73 & 95 & 2 & - & 10 & 5 & 16 & - \\
\hline Bienes de consumo $\ldots \ldots \ldots$ & 53 & 69 & 9 & 6 & 18 & 24 & 20 & - \\
\hline $\begin{array}{l}\text { Aplicaciones civiles de la ener- } \\
\text { gía atómica } \quad \ldots \ldots \\
\ldots\end{array}$ & 24 & 69 & 27 & 8 & 20 & 22 & 29 & - \\
\hline Aeronáutica $\ldots \ldots \ldots \ldots \ldots$ & 30 & 56 & 16 & 4 & 25 & 41 & 29 & - \\
\hline $\begin{array}{llllllll}\text { Militar } & \ldots & \ldots & \ldots & \ldots & \ldots & \ldots & \ldots\end{array}$ & 14 & 30 & 32 & 31 & 30 & 39 & 23 & - \\
\hline $\begin{array}{lllllll}\text { Espacial } & \ldots & \ldots & \ldots & \ldots & \ldots & \ldots\end{array}$ & 23 & 49 & 23 & 16 & 30 & 35 & 24 & - \\
\hline
\end{tabular}


tereotipos que se encuentran alejados con frecuencia de un nivel de conocimientos suficiente. Por lo tanto, el cambio de imagen no sólo ha de producirse mediante el incremento del nivel de conocimiento de la población, sino también mediante la alteración a través de técnicas comunicativas de tales estereotipos.

Ahora vamos a analizar una serie de resultados referentes tan sólo a las opiniones de los diputados, ya que, por el grado de conocimiento que requiere tener una opinión cualificada sobre diversos temas relacionados con la ciencia, pareció oportuno en la fase del diseño de la investigación no formular determinadas preguntas a la población.

Un primer indicador que vamos a analizar incide en el controvertido tema de si España debiera dedicar sus recursos científicos a realizar investigación básica o bien, por el contrario, abandonar este área, ya que otros países, por su tradición y riqueza, siempre irán por delante de la ciencia española. En concreto, la pregunta que se formuló a los diputados se hizo en los siguientes términos: "Se ha dicho que en un país como España no hay recursos para la ciencia pura, descubrir nuevas teorías, conceptos nuevos, etc.; que lo único que podemos y debemos hacer es investigar la aplicación práctica a problemas nuestros de lo que ya han descubierto en otros países, ¿cree usted que los que dicen eso tienen toda la razón, bastante razón, están equivocados, están completamente equivocados?» Las respuestas se distribuyen tal como aparecen en la tabla 17.

\section{TABLA 17}

Grado de acuerdo de los diputados con la idea de que la ciencia española sólo debe investigar problemas aplicados, dejando los problemas básicos para que los trabajen los científicos extranjeros

Los que realizan tal afirmación

Tienen toda la razón

Tienen bastante razón

Están equivocados ...

Están completamente equivocados
$\%$ 5 38

18

Las opiniones de los diputados se dividen entre la aceptación del supuesto de que en España no hay que realizar ciencia básica y la de que rechazan dicha noción: Es más, estos últimos, es decir, los que consideran que sí se debe hacer ciencia básica, son más numerosos (el 58 por 100) que los 
que opinan de forma pesimista, y que representan el 43 por 100. No deja de ser interesante constatar que los diputados que con mayor énfasis apoyan la idea de la ciencia aplicada, esto es, los que responden «tienen toda la razón», son todos docentes, de UCD y AP, mientras que la mayor proporción de los que se oponen a tal noción se encuentra entre los diputados del PSOE, con el 65 por 100 . Son resultados que presagian una fuerte polémica parlamentaria cuando se debatan los objetivos de la investigación científica española.

Otro tema relevante sobre la ciencia española es el de la comparación de las características que definen, respectivamente, a los investigadores españoles de sus homónimos extranjeros. La pregunta se formuló del siguiente modo: «Comparando los investigadores extranjeros con los investigadores españoles que ocupan, relativamente, igual posición y se dediquen a la misma actividad, ¿en qué se diferencian, favorablemente y desfavorablemente, los extranjeros en los aspectos de la siguiente lista?» Las respuestas dadas por los diputados a los diferentes aspectos propuestos se contienen resumidas en la tabla 18.

Una primera lectura de los resultados obtenidos revela la pobre opinión que los diputados tienen de los científicos españoles al compararlos con los investigadores extranjeros — la comparación se realiza, automáticamente, con los de países occidentales avanzados, que son siempre el referente español para «lo extranjero»-. El mayor grado de acuerdo se produce, con el 91 por 100 , al reconocer que en otros países se dispone de más medios materiales para investigar que en España. Pero es que, además, y siempre según la opi-

\section{TABLA 18}

Opinión de los diputados sobre el grado de favorabilidad resultante de la comparación de los investigadores españoles

con los investigadores extranjeros

\begin{tabular}{|c|c|c|c|c|}
\hline \multirow[b]{2}{*}{ Aspectos de la comparación } & \multicolumn{4}{|c|}{ LOS CIENTIFICOS EXTRANJEROS SON } \\
\hline & $\begin{array}{c}\text { Relativamente } \\
\text { superiores } \\
\text { a los } \\
\text { españoles }\end{array}$ & $\begin{array}{c}\text { Relativamente } \\
\text { inferiores } \\
\text { a los } \\
\text { españoles }\end{array}$ & Igual & NC \\
\hline Medios disponibles para investigar ... & 91 & 1 & 一 & 8 \\
\hline Preparación científica general $\ldots \ldots \ldots$ & 61 & 13 & 1 & 25 \\
\hline Dominio técnicas investigación $\ldots \ldots$ & 70 & 4 & i & 25 \\
\hline Interés por su trabajo científico $\ldots \ldots \ldots$ & 39 & 15 & 1 & 45 \\
\hline Capacidad para organizar su trabajo ... & 55 & 7 & 1 & 38 \\
\hline $\begin{array}{lllllllll}\text { Dedicación } & \ldots & \ldots & \ldots & \ldots & \ldots & \ldots & \ldots & \ldots\end{array}$ & 57 & 10 & - & 33 \\
\hline Grado colaboración con colegas $\ldots \ldots$ & 63 & 1 & - & 33 \\
\hline Deseo de ayudar investigadores jóvenes. & 50 & 9 & 1 & 40 \\
\hline $\begin{array}{lllllllll}\text { Productividad } & \ldots & \ldots & \ldots & \ldots & \ldots & \ldots & \ldots\end{array}$ & 57 & 8 & - & 34 \\
\hline $\begin{array}{llllllllll}\text { Originalidad } & \ldots & \ldots & \ldots & \ldots & \ldots & \ldots & \ldots & \ldots\end{array}$ & 21 & 45 & - & 33 \\
\hline
\end{tabular}


nión de los diputados, los investigadores extranjeros están más preparados, en términos generales, para el trabajo científico que los investigadores españoles, dominan mejor las técnicas de trabajo, tienen mayor capacidad para organizar sus investigaciones, están más dedicados a su labor, son más solidarios con sus colegas y con los investigadores jóvenes y son más productivos. Tan sólo en un aspecto consideran los diputados que los investigadores españoles superan a los investigadores extranjeros, y es en la originalidad de su trabajo. Toda una concesión al estereotipo del genio de la raza hispana.

Dado que se trata de opiniones emitidas por los máximos representantes políticos de la sociedad española, no cabe otra cosa que concluir que el complejo, y sentimiento, de inferioridad de los españoles en materia científica son muy profundos, y que nos encontramos ante un «mal social», el del pobre desarrollo y precaria organización de la ciencia española, que sólo podrá ser atajado desde un planteamiento de superación y esfuerzo colectivo.

El cambio de régimen político, en la última mitad de la década de los setenta, abrió las puertas del retorno a España de los numerosos y destacados españoles que, tanto por motivos políticos como por otros estrictamente profesionales, llevaban muchos años investigando en centros de trabajo extranjeros. Hubo un momento de euforia en el que se pretendió que volvieran a la Universidad española los Ochoa, Grande Covián y tantos otros que desempeñan brillantes puestos de trabajo, sobre todo en los Estados Unidos. Pero han pasado los años, los grandes investigadores españoles residentes en el extranjero no se han reintegrado plenamente a las instituciones de investigación españolas, y la euforia ha remitido notablemente. Esta situación nos condujo a preguntar a los diputados lo siguiente: «Se ha hablado mucho de la vuelta de investigadores españoles en el extranjero. De hecho, parece que pocos han vuelto, ¿cómo se explica esto?», las opiniones de los diputados al responder a dicha pregunta se han distribuido de la forma en que se resume en la tabla 19.

\section{TABLA 19}

Causas que, según los diputados, ban impedido que retornen los investigadores españoles en el extranjero

Faltan medios científicos

Falta política adecuada

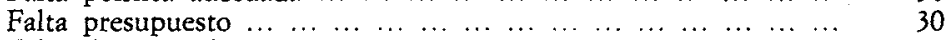

$\begin{array}{lllllllllllllllll}\text { Falta de estímulo } & \ldots & \ldots & \ldots & \ldots & \ldots & \ldots & \ldots & \ldots & \ldots & \ldots & \ldots & \ldots & \ldots & \ldots & \ldots & \ldots \\ \end{array}$

\begin{tabular}{lllllllllllllll} 
Escasa retribución & $\ldots$ & $\ldots$ & $\ldots$ & $\ldots$ & $\ldots$ & $\ldots$ & $\ldots$ & $\ldots$ & $\ldots$ & $\ldots$ & $\ldots$ & $\ldots$ & $\ldots$ & 8 \\
\hline
\end{tabular}

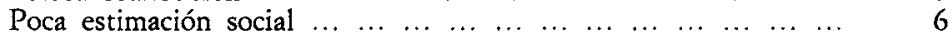

$\begin{array}{lllllllllllllllll}\text { Faltan equipos } & \ldots & \ldots & \ldots & \ldots & \ldots & \ldots & \ldots & \ldots & \ldots & \ldots & \ldots & \ldots & \ldots & \ldots & & 4\end{array}$ 
La ausencia de una política científica adecuada, que se traduzca en un incremento de los por ahora precarios medios materiales de que disponen los científicos españoles, es la principal causa de que no se haya consolidado el retorno de los investigadores españoles en el extranjero. Otras causas, tales como la escasa retribución, la poca estimación social, la falta de estímulo y de equipos, son aspectos complementarios que refuetzan la acción negativa de esa causa fundamental que es la ausencia de una política científica avan. zada y coherente, y la escasez de unos presupuestos claramente insuficientes.

Las soluciones que los diputados proponen para aprovechar mejor el trabajo de esos investigadores que trabajan en el extranjero se contienen en las respuestas dadas a la siguiente pregunta: "Considerando los investigadores españoles de prestigio que trabajan actualmente en el extranjero, ¿cómo cree usted que serían más eficaces para impulsar la investigación en España?» Las respuestas dadas se han distribuido del modo que se contiene en la tabla 20.

\section{TABLA 20}

Acciones que, en opinión de los diputados, babria que emprender para que los investigadores españoles en el extranjero ayudasen a impulsar la investigación en España

Acciones a emprender

Creando centros de investigación en España dirigidos u orienta-

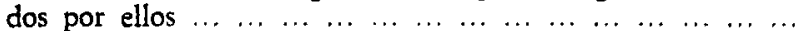

Trabajando temporadas regulares en España sin abandonar sus puestos en el extranjero

Formando investigadores españoles en los países extranjeros don-

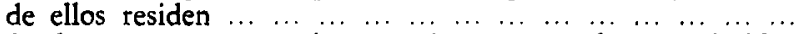

Sirviendo como asesores a los organismos españoles que deciden

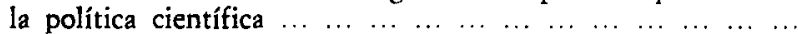

Volviendo definitivamente a España, para integrarse en algún

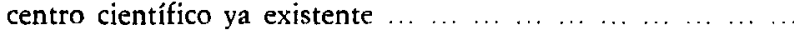

Otras

NC
$\%$

30

20

13

14

11

4

3

(106)

El grupo más numeroso de diputados (el 30 por 100) considera que la mejor forma de aprovechar eficazmente el trabajo de los científicos españoles residentes en el extranjero consiste en crear nuevos centros de investigación que queden bajo la dirección de los mismos. Otro grupo de diputados (el 20 por 100) es partidario de una acción que puede, eventualmente, ser complementaria con la anterior, y que consiste en que tales investigadores 
trabajen durante temporadas reguladas en centros españoles, pero sin desvincularse de los puestos de trabajo que desempeñan en los centros extranjeros.

Los partidarios de que los científicos residentes en el extranjero vuelvan a España y se integren en centros de investigación ya existentes forman un grupo minoritario del 11 por 100 , lo que parece indicar que una mayoría de diputados no considera viable esta fórmula por los repetidos fracasos que ha cosechado en experiencias anteriores. Otros dos grupos de diputados, que representan el 18 y el 14 por 100 , respectivamente, son partidarios de que los investigadores españoles en el extranjero no abandonen sus puestos de trabajo para que desde ellos ayuden a los jóvenes investigadores que desean perfeccionarse en el extranjero, actuando así como una especie de puente para los investigadores que desean ampliar sus conocimientos, o bien ayuden a las autoridades españolas en el diseño de una política científica más conveniente y apropiada que la actual.

En definitiva, la diversidad de preferencias de actuación que muestran las diputados pone de manifiesto que, muy probablemente, la mejora de la eficacia de la política científica española, y un mejor aprovechamiento de las experiencias de los investigadores españoles de prestigio que residen en el extranjero, se han de conseguir llevando a cabo acciones complementarias que se refuercen unas a otras, dentro de una línea de desarrollo científico más racional que la actual. 